Article

\title{
Spin-Offs, Innovation Spillover and the Formation of Agricultural Clusters: The Case of the Vegetable Cluster in Shouguang City, Shandong Province, China
}

\author{
Erling $\mathrm{Li}^{1,2}$, Yanan $\mathrm{Xu}^{3}$, Shixin $\operatorname{Ren}^{4}$ and Jay Lee ${ }^{5, * \mathbb{D}}$ \\ 1 Key Research Institute of Yellow River Civilization and Sustainable Development \& Collaborative Innovation \\ Center on Yellow River Civilization of Henan Province, Henan University, Kaifeng 475001, China; \\ erlingli@henu.edu.cn \\ 2 Key Laboratory of Geospatial Technology for the Middle and Lower Yellow River Regions, \\ Institute of Sustainable Development in Agriculture and Rural Area, Henan University, \\ Kaifeng 475004, China \\ 3 College of Resources and Environment, Henan University of Economics and Law, Zhengzhou 450046, China; \\ 20170038@huel.edu.cn \\ 4 Business School, Henan Normal University, Xinxiang 453007, China; renshixin@htu.edu.cn \\ 5 Department of Geography, Kent State University, Kent, OH 44242, USA \\ * Correspondence: jlee@kent.edu; Tel.: +330-672-3222
}

Citation: Li, E.; Xu, Y.; Ren, S.; Lee, J. Spin-Offs, Innovation Spillover and the Formation of Agricultural Clusters: The Case of the Vegetable Cluster in Shouguang City, Shandong Province, China. Land 2022, 11, 279. https://doi.org/10.3390/land11020279

Academic Editors: Le Zhang and Yasuyuki Kono

Received: 5 January 2022

Accepted: 9 February 2022

Published: 11 February 2022

Publisher's Note: MDPI stays neutral with regard to jurisdictional claims in published maps and institutional affiliations.

Copyright: (C) 2022 by the authors. Licensee MDPI, Basel, Switzerland. This article is an open access article distributed under the terms and conditions of the Creative Commons Attribution (CC BY) license (https:// creativecommons.org/licenses/by/ $4.0 /)$.

\begin{abstract}
Agricultural clusters play a powerful role in promoting the agricultural transformation and rejuvenation of rural areas. However, no in-depth exploration has been made on how agricultural clusters form and evolve, especially in the context of China's long-term small-scale rural economy. The purpose of this article is to reveal the formation process and evolution mechanism of agricultural clusters by case study research. With the knowledge flow as the starting point, this article takes the Vegetable Cluster in Shouguang City of Shandong Province, China as an example to construct a theoretical framework in the three dimensions of points (spin-offs of enterprises or farmers), lines (network-spillovers of various innovation) and planes (the formation of new regional industry spaces) and put forward theoretical hypotheses. It is shown that: (1) The local spin-off of seed farmers is the main path in the transformation of traditional farmers into enterprises. (2) The network-spillover and adoption of innovative knowledge promote the derivation of specialized farmers or enterprises and realize regional agricultural specialization and spatial agglomeration. (3) The formation of the agricultural cluster resulted from the joint effects of spin-off derived from the entrepreneurial spirit of the farmers, network-spillover of various agricultural innovations and spatial integration of the agricultural landscape. The formation of local agricultural innovation systems marks the maturity of an agricultural cluster. This article contribute to the field by studying one source of Alfred Marshall's knowledge of external economy from the perspective of spin-offs and innovative spillovers, analyzing the agricultural increasing returns to scale neglected by Krugman, and exploring the micro mechanism of farmers' enterprise-oriented evolution and the formation of agricultural clusters in underdeveloped rural areas. The research results are of profound referential significance for the cultivation of agricultural clusters in developing countries.
\end{abstract}

Keywords: spin-offs; innovation spillover; agricultural cluster; vegetable cluster in Shouguang City; Shandong Province; China

\section{Introduction}

Cluster initiatives are starting to be seen as a key approach to help advance all sectors of many countries [1-7]. As global agriculture has continuously demonstrated a clustering trend, agricultural clusters have increasingly attracted the attention of the academic world and have become a strategic tool for many developing countries to increase their agricultural international competitiveness $[2,8]$. 
In recent years, such bottlenecks as land, capital, and technology in China's agricultural development have become increasingly prominent. As a new agricultural organization mode, agricultural clusters have become an effective carrier for China to solve these problems and carry out a joint development of primary, secondary, and tertiary industries. In the economic development of China's rural areas, the emergence of specialized villages and agricultural clusters plays an important role [9], especially in recent years, and the country's policies on such issues as moderate scale management (1997), land circulation (2004), cultivation of new business entities (2014) and separation of the three rights (2016) have accelerated the formation of agricultural clusters.

Agricultural clusters promote agricultural transformation, industrial spatial reconstruction, and the economic and social development of rural areas with their unique advantages. With a large scale and specialization, they not only make up for Chinese rural economic shortcomings, including small-scale farmland, decentralized operation, and low organization levels, but also promote the industrialization and urbanization of rural areas, absorb surplus rural labor, and increase farmers' income. The integration of small-scale farmers achieves the connection between small-scale production and large markets, thus promoting the transformation of China's agricultural and agricultural development modes.

How are agricultural clusters formed? How have they evolved? During our survey, we found that traditional farmers in China's small-scale farmers' economy have evolved into enterprise-type farmers or agricultural enterprises by accepting and adopting new knowledge. There have also been spillovers of the innovative technology and new knowledge through spin-off networks, thus forming a development path that deviates from the original. Creation is a key to the formation of agricultural clusters and the industrial spatial reconstruction of rural areas is the result of agricultural clusters. Then, in rural communities, how is new knowledge generated and how does it spread through network spillovers? How is it widely adopted by farmers to form agricultural clusters? The answers to these questions are of great significance to further cultivate agricultural clusters and modern agriculture development in developing countries.

\section{Literature Review}

Industrial clustering has always been a core topic in the research of economic geography. Since the 1980s, with scholars' rediscovery of Marshall's 'industrial districts' in the context of globalization, 'industrial clusters' have quickly become a research hotspot in geography, economics, and management. They have dominated international mainstream research in economic geography. A large domestic and foreign literature has provided in-depth explorations of the source of industrial clusters' competitive advantages, conditions for their production, regional growth effects, network organization, technological innovation, etc. [10-19].

As for the formation mechanism of industrial clusters, as early as over 100 years ago, the industrial district theory pioneered by Marshall focused on the clustering of many similar small enterprises with the division of labor in specific regions [20]. Based on the assumption that the returns to scale of neoclassical economics remain unchanged, the theory attributes the advantages of enterprise clustering to the external economy of enterprises, but does not delve into where these external economies might come from.

The New Industrial District School [21] emphasized the influence of local socio-cultural factors on the learning mechanism of industrial clusters. It focused on the rooting of enterprises in the local community environment and the continuous emergence of labor division and professionalization, but did not explain how an enterprise is rooted in local culture and how it works.

The Competitive Strategy School of Porter (1990) [11] emphasized the 'Diamond Model' which identifies national competitive advantages based on industrial clusters, which include groups of interconnected companies, suppliers, related industries, and organizations in specific regions. This model has become a new approach for enterprises 
and governments to assess regional competitive advantages, but it weakens the spatial dimensions of clusters.

Krugman's New Economic Geography School [22] described the forward and backward connections of industries and industrial clustering caused by labor flows. However, it ignored the importance of technological spillovers and held that agriculture involves constant returns to scale, which is inconsistent with the reality of the growth and clustering of agriculture.

It can be seen that most of the existing literature focuses on industrial clusters in the high-tech, manufacturing, service, and creative industries [10,12-14,16,19,23]. Remarkably, little attention has been paid to clusters in the agricultural sector [2,7,19]. Although some international literature does use cases in the agricultural sector [11,15], they focus on the manufacturing industry due to the high industrialization degree and advanced agricultural product processing in the case areas.

Existing literature seldom separates agricultural clusters from manufacturing clusters, which means that it ignores the differences between agriculture and manufacturing in terms of cluster formation, evolution, and development. Agriculture has different characteristics from other industries in many key elements of cluster formation such as the actor, product type, industrial chain, and local rooting. For example, the basic actor of agricultural clusters is a farmer (or family farm) with characteristics such as enterprise operation, natural geographical clustering, local rooting, and the reproduction and dissemination capabilities of rural communities. The hierarchy between farmers and actors (such as leading enterprises) is more obvious; the agricultural chain is long and complicated (Stringer C. and Heron R, 2008), and involves more plans and government promotions (compared with manufacturing clusters). Therefore, the formation and evolution of agricultural clusters certainly have their own laws and uniqueness.

In the context of the small-scale rural economy, China's agricultural clusters are formed involving a large number of farmers. In this regard, the evolution of farmer organizations into enterprises is the key (first step) to the formation of agricultural clusters. Previous research into cluster evolution mainly focused on the cluster and network levels, paying little attention to the evolution of enterprise (or farmer) organizations in clusters. Existing research on cluster evolution also did not consider the heterogeneity of enterprises (or farmers) capacity (including scale, rights, and absorption capacity). In other words, the 'black box' of enterprises (or farmers) has not been opened. The status of industrial development in China's rural areas is characterized by a large number of specialized village clusters and few mature agricultural clusters, so specialized villages should be upgraded into industrial clusters through the organization and integration of industrial networks. This issue has not yet attracted enough attention from scholars.

Agricultural clusters are often spontaneous spin-off clusters. Existing research into spinoffs focuses on how enterprises in a cluster or industry are spun off. That is to say, clusters or industries are regarded as established. However, it should be noted that there is little research into how spin-offs form new clusters or industries through knowledge spillovers. To this end, with spin-offs and innovative spillovers as a conceptual breakthrough, this article takes the Vegetable Cluster of Shouguang City, Shandong Province as an example and delves into the formation process and evolution mechanism of agricultural clusters by case study research based on data gathered from field interviews and statistical yearbooks.

The field interviews attempted to answer key questions:

1. How do traditional farmers transform into enterprises in rural areas?

2. How do traditional farmers engage in new industries through knowledge spillovers and spin-offs from innovative farmers?

3. How do farmers and agricultural enterprises promote the formation and evolution of agricultural clusters through spin-offs and innovation spillovers?

By answering these questions, an in-depth analysis can be made of the enterpriseoriented evolution of farmer organizations, the formation of industrial networks and the spatial reconstruction process of the cluster industry, and a theoretical basis and practical 
references can be provided for the formation of agricultural clusters in other agriculturebased developing countries.

\section{Theoretical Framework and Research Hypotheses}

\subsection{Connotations and Characteristics of Agricultural Clusters}

An industrial cluster is a geographic concentration of inter-connected companies and institutions in a particular field [2,11]. Agricultural clusters are an extension and application of the industrial cluster theory in the agricultural sector. It has the essential characteristics of industrial clusters, including geographical proximity and industrial correlation [23]. Specifically, industrial cluster $=$ industrial agglomeration + network [24]. First, the geographic agglomeration of interdependent small and medium-sized enterprises and institutions is a precondition; second, highly specialized labor division and cross-industry development are distinguishing features; and third, the local social network provides a deep foundation $[17,25]$. Thus, an agricultural cluster is simply a concentration of producers, agribusinesses, and institutions that are engaged in the same agricultural or agro-industrial subsector, and interconnect and build value networks when addressing common challenges and pursuing common opportunities [2]. Agricultural clusters include enterprises (or farmers and family farms operating as enterprise) that produce and process agro-products, related agricultural distribution enterprises, sales service enterprises, raw material and equipment suppliers, R\&D centers, testing centers, universities, vocational training providers, suppliers of specialized inputs (such as components, machinery, and services), and providers of specialized infrastructure, governmental, and other institutions [2].

Different from traditional agriculture, agricultural clusters have such characteristics as the specialization of agricultural production, enterprise-orientation of agricultural production and operation actors, commercialization of agricultural products (similar to the commercial agriculture in western literature), and integration of agricultural operations.

Different from the industrial clusters of other sectors, agricultural clusters integrate the characteristics of the primary, secondary, and tertiary industries, namely agricultural product cultivation or the breeding industry, agricultural product processing, and related services before and after production. Therefore, there is a longer network industrial chain in the agricultural cluster. As the upstream products of agricultural clusters are characteristic agricultural products, farmers operating as enterprises are the basic production actors and agricultural clusters are easily affected by natural disasters; the differences in climate, market, technological innovation conditions, etc. in different regions shape the strong regional and localized characteristics of agricultural clusters.

It can thus be seen that the formation and evolution of agricultural clusters include the transformation of farmers into enterprises, the extension of industrial chain and the formation of network based on the agglomeration of enterprises (or farmers), and the co-evolution with cluster regions in technology, institution, and space [19]. The advantages of agricultural clusters come not only from the advantages of the geographical clustering of small and medium-sized enterprises and farmers), but also from the networking and interaction of various entities within the cluster; namely, agricultural cluster = agricultural agglomeration + industrial network [24]. Agricultural clusters are closely related to, and share the same goals as, the rural policies that China currently advocates. These policies include promoting integrated development of primary, secondary, and tertiary industries in rural areas, the reconstruction of the entire industry chain, and rural rejuvenation.

\subsection{Spin-Offs}

The attention to spin-offs in industrial cluster research began with research into the spin-offs of high-tech industrial clusters in America's Silicon Valley [26-28]. It emphasized that companies with leading roles (such as the first semiconductor lab founded by 1955 Nobel Laureate in Physics Shockley in Silicon Valley) are seeds from which myriad new semiconductor companies had spun off; they were interconnected and continuously clustered together to form the Silicon Valley cluster. 
Spin-offs in agricultural clusters comprise the process by which the entities in the cluster breed and produce sub-entities (including farmers, agricultural enterprises, logistics companies, institutions, and organizations) which engage in industrial activities similar or related to theirs in various forms. Traditional farmers only produce traditional crops at the beginning. Once seed farmers playing a leading role in bringing new knowledge of an agricultural product (such as strawberries) to a certain place, such innovative knowledge would spread through social, administrative, technical, and management channels (or relations). The spread of the new knowledge that is imitated and adopted by the farmers diffuses through the aforementioned channels. Farmers who adopt such new knowledge from seed farmers and other channels, change their production mode from self-sufficient production to commercial production of a particular agricultural product. In this manner, the organizational form of agricultural production becomes enterprise-oriented, realizing organizational innovation and product innovation.

Therefore, hypothesis 1 is proposed:

Hypothesis 1. The local derivation of seed farmers is the main way of the transformation of traditional farmers into enterprises. In the process of knowledge flow, the dissemination and diffusion of knowledge are manifestations of economic externality; the adoption of knowledge is the essential process in which new industrial actors are spun off from the original actors [19]. As such, the acceptability of new knowledge and the difficulty in farmers' adoption of new knowledge are the keys to the emergence of spin-offs.

\subsection{Innovative Spillovers}

The spillover effect of innovation plays a vital role in the development of an economy, as recognized and stressed by the endogenous growth models [29]. 'Innovative spillovers' mainly refers to the process in which innovative knowledge and success in such aspects as information, technology, management, and organizational forms related to production and operation activities are shared, spread, and imitated rapidly. Grossman and Helpman (1991) believed that innovation spillovers were an enterprise's free access to other enterprises information without market transactions [30].

The process of spillovers mainly includes the knowledge spillover of the 'source' and the learning and absorption by the 'receiver'. When the knowledge is received and adopted by the receiver to form a new organization, the spin-off process begins, and the utility of spillovers is maximized. It is more effective if innovative knowledge spills through the spin-off channels.

Knowledge spillovers are not limited to the high-tech industry [31] or cities, and are common in traditional rural communities. In China's traditional agricultural areas, the proximity among households within a village or town often affects how well knowledge travels among households to facilitate innovation. Whether via the Marshall-Arrow-Romer (MAR) spillover, which focuses on the spillover from different firms in a common industry, or the Jacobs spillover, which focuses on the spillover from different individuals in different industries [31], innovative knowledge can travel in the air and spread among farmers in a barrier-free way. It would first be adopted by a few farmers and then gradually adopted by more [19]. Since farmers live in the same rural community for a long time and have natural agglomeration characteristics, innovation spillover leads to the spatial agglomeration of farmers who adopt innovative knowledge and produce similar products.

Therefore, hypothesis 2 is proposed:

Hypothesis 2. The network-spillover and adoption of innovative knowledge promote the derivation of specialized farmers or enterprises and realize regional agricultural specialization and spatial agglomeration. 


\subsection{Interaction among Spin-Offs, Innovative Spillovers, and the Formation of Agricultural Clusters}

In rural areas, the enterprise-oriented evolution of farmers is the first step in the formation of agricultural clusters. Spin-offs turn traditional farmers into agricultural entrepreneurs, or collectively into institutions, which increase the number of local actors (points) (Figure 1).

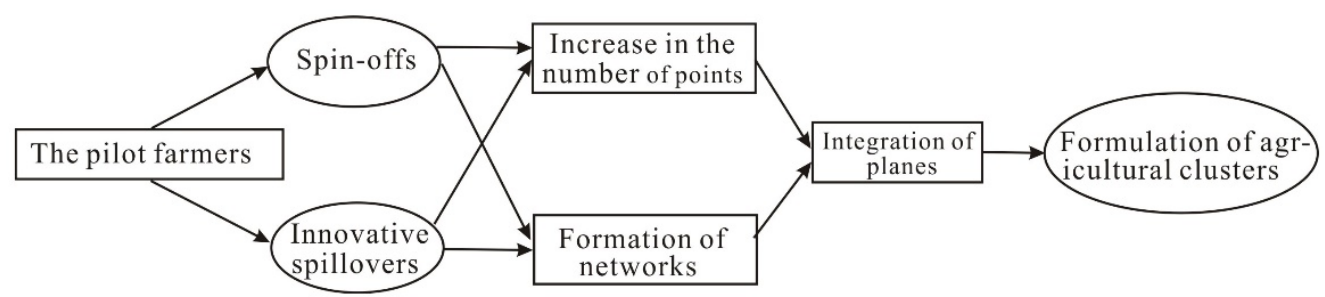

Figure 1. Interaction among spin-offs, innovative spillovers, and the formation of agricultural clusters.

Due to the complexity of new knowledge and the receptivity of farmers with different knowledge levels, spin-offs are hierarchical. Farmers with a high absorption capacity can adopt highly complex new knowledge and are spun off into high-level actors [32]. As such, the hierarchy of spin-offs increases the types of start-up actors and forms related diversification [33]. This is the key to the increase in the number and types of companies or institutions (i.e., points) in agricultural clusters. On the basis of spin-off networks, diversified actors further develop into cooperative networks and innovative networks (i.e., lines), which are the basic framework for the formation of agricultural clusters [19].

Compared with other industries, agricultural clusters are site-driven. Agricultural products are produced on farmers' contracted land and are sometimes processed in their own yards. Farmers transforming into entrepreneurs or institutions on the basis of rural clusters are naturally characterized by clustering. Agricultural production has explicit knowledge characteristics. The tightly netted rural communities provide the convenience for the spread and spillover of innovative knowledge. As a node in clusters, the government accelerates the maturing of agricultural clusters by promoting a regional innovation environment, constructing agricultural innovation systems, and integrating the industrial space.

Therefore, the formation of the agricultural cluster resulted from the joint effects of spin-off derived from the entrepreneurial spirit of the farmers, network-spillover of various agricultural innovations, and spatial integration of the agricultural landscape. From the perspective of knowledge flows, the innovation of original farmers (or pilot farmers) is a process of knowledge creation and recreation. The innovative spillover is a process of diffusing innovative knowledge, while the spin-off is a process of adopting innovative knowledge. Spin-offs are the effective results of innovative spillovers, while innovation spillovers are an important guarantee for the formation of spin-off networks and innovative networks. Pilot farmers increase the number of new actors (points) through spin-offs, and promote the formation of networks (lines) through innovative spillovers. The expansion of the scale of industry causes the government to integrate industrial spaces (planes). As illustrated in Figure 1, they interact to jointly promote the formation of agricultural clusters and the construction of local agricultural innovation systems.

Therefore, hypothesis 3 is proposed:

Hypothesis 3. The formation of local agricultural innovation system marks the maturity of agricultural clusters.

\section{Methodology, Data Source, and Formation of the Case Cluster}

\subsection{Methodology}

Case study research is a set of predefined procedures, steps, the study of a particular experience, and demonstration projects [34]. Agricultural cluster development process is divided into four phases using time series analysis technology. In order to verify the 
hypotheses of this article, the contribution of spin-off and innovation spillover to the formation of agricultural clusters in each stage was analyzed.

\subsection{Data Source}

The data of this research came from five field surveys and follow-up interviews conducted by the author and students at the Vegetable Cluster of Shouguang, Shandong from November 2012, to December 2019. A total of 16 enterprises, 35 farmer households, and 12 managers from the Bureau of Agriculture, Science and Technology Bureau, and village governments were surveyed. The specific objects investigated include vegetable growers, farmer specialized cooperatives, seedling cultivation enterprises, agricultural materials distribution enterprises, vegetable trading markets, industry associations, Agriculture Bureau, Science and Technology Bureau, township/street office government, village committees, and other administrative staffs. Questions related to spin-off, innovation spillover, and industrial cluster development are designed in the questionnaire. For example, which farmers have influenced you to get involved in the vegetable industry? Which farmers were influenced by you to go into the vegetable industry? What are your sources of technology? In addition, the statistical data used came from Shouguang Statistical Yearbook, Shouguang Statistical Bulletin of National Economic and Social Development and the official website of the local government from 2005 to 2019.

\subsection{Stages of Formation of Shouguang Vegetable Cluster}

Shandong Shouguang Vegetable Cluster is adjacent to Bohai Bay in the north central area of the Shandong Peninsula in China (Figure 2). Shouguang has a long history of vegetable cultivation. Jia Sixie, a native of Shouguang and agronomist of the Northern Wei Dynasty, penned scientific and detailed discussions on vegetable cultivation in his agricultural masterpiece Qimin Yaoshu. In the Ming and Qing Dynasties, the early-spring leek was a tribute to the imperial court. By the middle of the Qing Dynasty, scallions, Malian leeks, carrots, melons, celery, and tomatoes had become important agricultural products of Shouguang. In the long-term practice of production, the vegetable growers accumulated rich experience in vegetable cultivation. After 1949, although the vegetable cultivation in Shouguang continued in its historical tradition, under the influence of the planned economy, fewer varieties of vegetables were planted, including mainly scallions, cabbages, and radishes. After 1978, the land contracting responsibility system was implemented in rural areas and farmers had the right to decide which varieties to plant; the Shouguang Government decided to vigorously develop the vegetable industry using the traditional techniques of local vegetable cultivation. The dissemination of technical knowledge was promoted in the area by training seed-household models (such as the 'Five Kings', i.e., the King of Leeks, King of Celery, King of Tomatoes, King of Lotus Roots, and King of Watermelons) and organizing inspection and learning activities for farmers. In this way, many vegetable farmers and enterprises were derived locally, forming a division of labor and cooperation network between villages. Shouguang City is one of the areas in China where agricultural industrialization, standardization, commercialization, and internationalization started the earliest. In 2019, Shouguang City had a permanent population of 1,109,200 and arable land of $133,440 \mathrm{hm}^{2}\left(1 \mathrm{hm}^{2}=10,000 \mathrm{~m}^{2}\right)$. The distribution characteristics of agricultural resources and the traditional planting habits of farmers in Shouguang have formed a hierarchical structure of 'vegetables in the south; grains in the center; salt and cotton in the north'. 


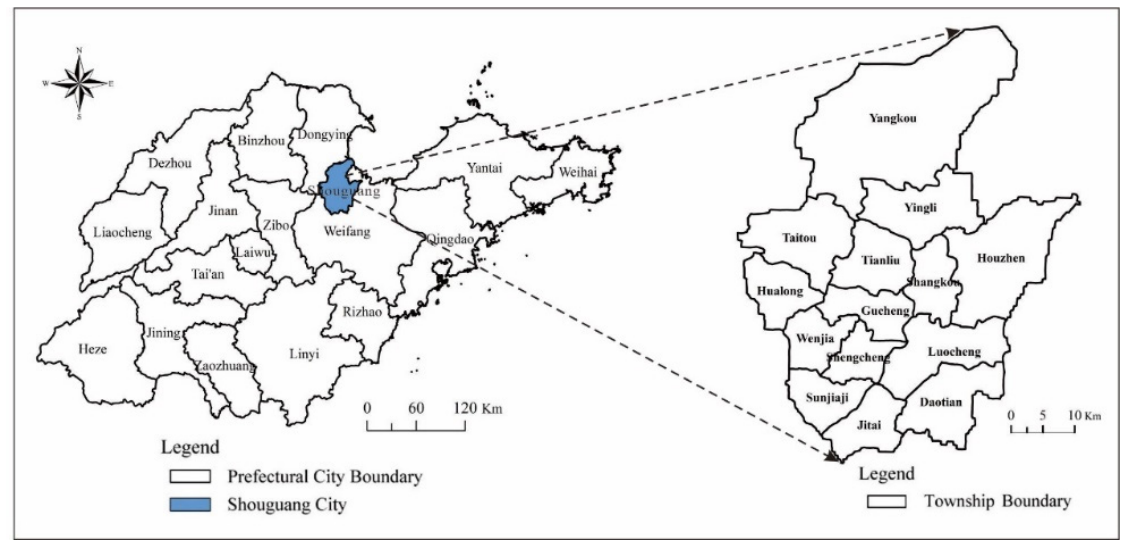

Figure 2. Location of the Shouguang Vegetable Cluster in Shandong Province.

According to the turning points of production technology in the development of the vegetable industry and the change of vegetable planting area and output value (Table 1 , Figure 3), the development of the Shouguang Vegetable Cluster after 1978 could be divided into four stages. The first stage (1979-1988) was characterized by the planting agglomeration of big field vegetables, in the second stage (1989-1995), specialized villages (SV ${ }^{1}$ ) emerged with the development of facility agriculture, the third stage (1996-2012) witnessed the formation of agricultural cluster, and the fourth stage (2013-present) saw the formation of agricultural innovative systems and spatial integration in the cluster. It can be seen from Table 1 and Figure 3 that the sown area and output of vegetables increased from $5850 \mathrm{hm}^{2}$ and 126,000 $\mathrm{t}$ in 1980 to $413,500 \mathrm{hm}^{2}$ and 3,572,600 $\mathrm{t}$ in 2019, respectively, in Shouguang city. Over a dozen vegetable production bases have been built, including Wanmu (about 1672 acres) Pepper, Wanmu Leek and Wanmu Celery, formed vegetable industry agglomeration area. There are a total of 587 specialized villages and towns such as 'China's First Town of Leeks', 'China's First Town of Radishes', and 'China's First Town of Cantaloupes'; there are over 410 leading agricultural enterprises and 2569 farmers' specialized cooperatives, leading more than $80 \%$ of farmers to enter the vegetable production system in the form of 'company (cooperative) + base + farmer' and driving the development of such related industries as the local seed industry, pesticides, food processing, agricultural implement machinery, and logistics, thus forming a closely-connected industrial network and a famous vegetable cluster.

Table 1. Profile of the primary industry and vegetable outputs in Shouguang city.

\begin{tabular}{cccccc}
\hline Year & $\begin{array}{c}\text { GDP (100 } \\
\text { Million } \\
\text { Yuan RMB) }\end{array}$ & $\begin{array}{c}\text { The Primary } \\
\text { Industry } \\
\text { (100 Million } \\
\text { Yuan RMB) }\end{array}$ & $\begin{array}{c}\text { Sown Area of } \\
\text { Vegetables } \\
\left(\mathbf{k h m}^{\mathbf{2}}\right)\end{array}$ & $\begin{array}{c}\text { Vegetable } \\
\text { Outputs } \\
\text { (Million kg) }\end{array}$ & $\begin{array}{c}\text { Rural Per } \\
\text { Capita Net } \\
\text { Income } \\
\text { (Yuan RMB) }\end{array}$ \\
\hline 1986 & 8.8 & 4.3 & 12.6 & 600.0 & 515 \\
1989 & 16.3 & 5.8 & 15.0 & 1200.0 & 809 \\
1992 & 30.1 & 11.0 & 19.3 & 1250.0 & 1256 \\
1995 & 53.0 & 17.2 & 32.5 & 2050.0 & 2826 \\
1998 & 81.0 & 25.1 & 37.7 & 2384.0 & 3650 \\
2001 & 116.1 & 28.6 & 57.0 & 3688.0 & 4256 \\
2004 & 182.4 & 36.4 & 54.5 & 3660.0 & 5016 \\
2007 & 316.1 & 46.9 & 50.6 & 3500.0 & 6619 \\
2010 & 470.3 & 67.0 & 51.8 & 4154.1 & 9495 \\
2013 & 701.2 & 86.4 & 52.1 & 4244.6 & 14,408 \\
2016 & 856.8 & 97.3 & 44.8 & 3911.5 & 17,652 \\
2019 & 768.1 & 101.2 & 41.4 & 3572.6 & 22,484 \\
\hline
\end{tabular}

Data source: Shouguang Statistical Yearbook in1987-2020. 


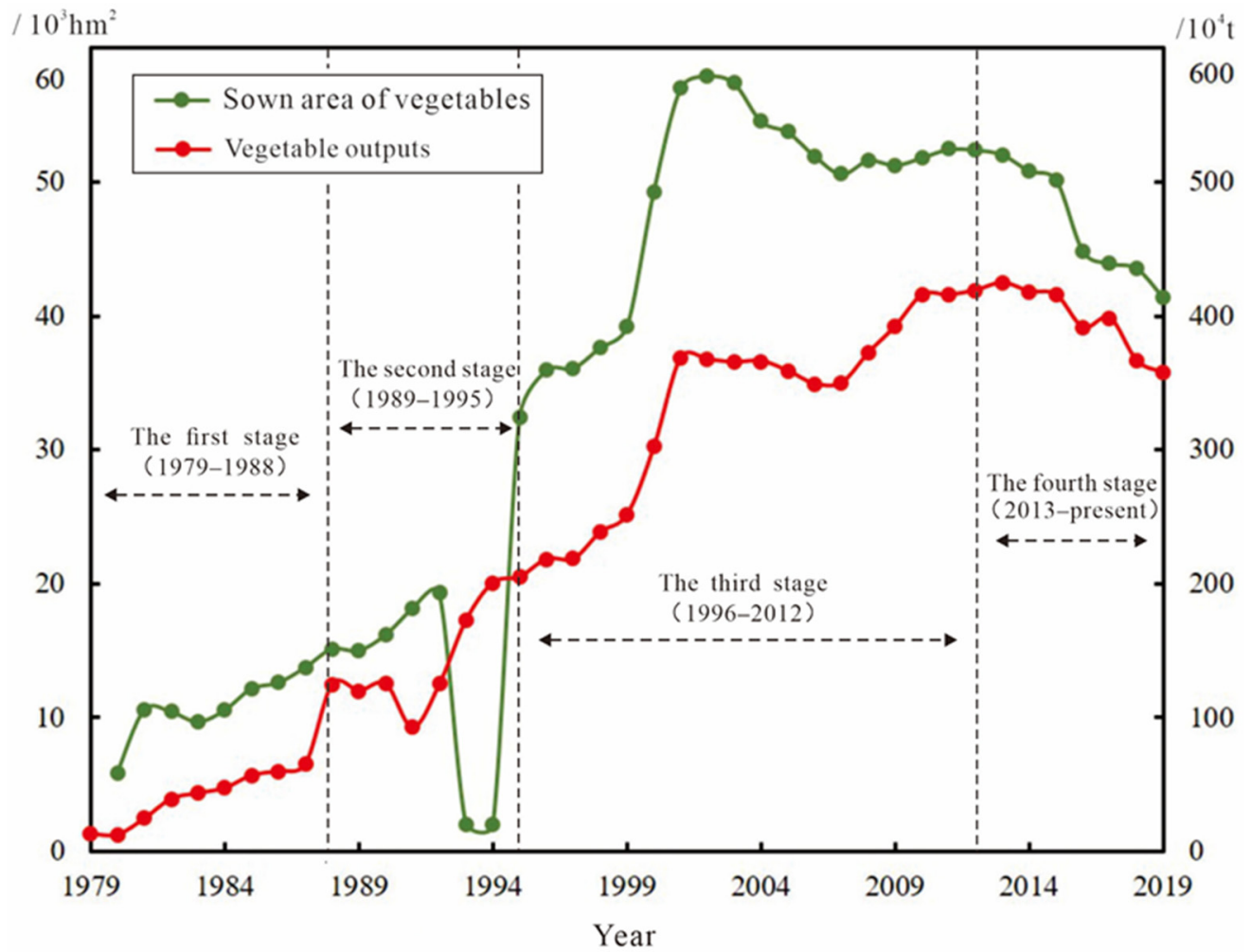

Figure 3. Formation and development stage division of vegetable industrial cluster in Shouguang city.

In the formation of the Shouguang Vegetable Cluster, the accumulation of technological experience, spillovers of innovative knowledge, and spin-offs of farmers (or companies) have played key roles. In particular, Shouguang City took the lead in successfully testing winter-warm greenhouse vegetable planting technology under the leadership of Wang Leyi of Sanyuan Village, starting a vegetable greenhouse revolution in China. It is a typical representative of facility agricultural clusters and green agricultural clusters. See Table 1 for the basic information of the primary industry and vegetable production values in Shouguang.

\section{Results}

4.1. Spin-Offs and Innovation Spillover in the Stage of Planting Agglomeration (1979-1988)

In this period, although the household contract responsibility system of China's arable land greatly liberated the productivity of rural areas, most rural households were still self-sufficient in cultivating traditional food crops for food and clothing. At the end of the 1980s, advocated by the local government, some transformed from planting traditional food crops to vegetable cultivation. Such practices spilled their cultivating technology through such social relations channels as kinship, friendship, and relationships among farmers in the same area, resulting in similar plantations. In this way, they realized the clustering plantation of the vegetable industry. With the increase in the farmers' capabilities, the pilot or pioneer farmers achieved organizational innovation and transformed into enterprises. On the one hand, spin-offs (or derivation) through social relations channels could reduce the risks of information acquisition and the difficulty of technology acquisition. On the other, financial support could be obtained through more intimate social relations.

From a conversation about carrot cultivation in Peiling Village, Mr. Pei, who had always cultivated traditional crops, heard that the carrots in other places were better than the local carrots. This prompted him to introduce carrot seeds from Tai'an County in Liaoning Province and try to cultivate them. When he made a profit, his younger brother and cousin who live in the same village began to imitate him, and asked him to buy some seeds for them. After a year, the profits from carrot cultivation outstripped those of other food crops. Although this news spread quickly, many rural households still hesitated and 
chose to wait and see out of uneasiness. At this time, Mr. Pei introduced three or four more barrels of seeds and divided them among five family members and friends for free, in the hopes that they would encourage their relatives and neighbors to plant carrots. In this way, the third batch of carrot farmers was formed. After 2 years, more and more rural households started to plant carrots in large areas. With continuous planting practice and problem-solving by both friends and relatives, Mr. Pei accumulated experience and formed and spread new knowledge, making him the 'King of Carrots' and 'Planting Consultant' trusted by government personnel and rural people alike.

In this process, Mr. Pei and his relatives and friends achieved resource innovation, product innovation and technological innovation, as well as encouraging many new carrot farmers (Figure 4), which stimulated a huge market demand for carrot seeds. At this point, Mr. Pei abandoned his own carrot planting and innovatively established a seed supply and marketing company, thereby obtaining higher added value and achieving organizational innovation and enterprise transformation. He also created more carrot farming rural households through selling seeds and disseminating his own planting experience and technology free of charge within the village through the spread of kinship and geographic relations, helping local carrot farming to achieve industrial agglomeration in Peiling Village and its surroundings.

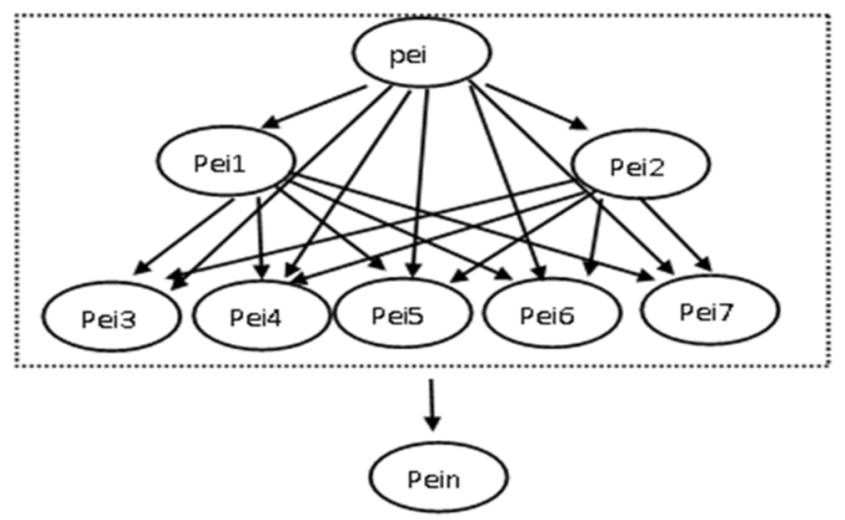

Figure 4. The spinoff process of carrot planting in Peiling village.

Similarly, the pilot farmers (seed-households, for instance the "five Kings" stated above) or enterprises had such spin-off and innovation overflow processes. By 1985, the number of vegetable varieties planted in the city had increased to more than 30 . However, since such climate conditions as temperature had a huge impact on vegetable cultivation, vegetable market transactions were seasonal, and the development of the vegetable industry was limited. By 1988, big field vegetables were planted on about $3333 \mathrm{hm}^{2}$ of arable land in the city, and the scale and efficiency of clustering were not high.

\subsection{Spin-Offs and Innovation Spillover in the Formation of a Specialized Village (1989-1995)}

After experiencing the development period of industry agglomeration, specialized agricultural products had grown to a larger scale than before in the village area and were able to obtain higher profits than traditional agriculture, attracting more rural households in the area to derive the same kind of farmers or family farms. However, this process can easily make an area become locked into that single practice or cause different kinds of negative influence. If local farmers with an entrepreneurial spirit can break from their dependence on the original path, they can carry out agricultural innovation and create new paths. For example, when pilot farmers with an entrepreneurial spirit seize upon new technology that is suitable for the area, they will transform and utilize it in the local area, and update their own cultivated products and production methods. They would become leading farmers in opening up local windows of opportunity (innovative planting projects). As a result, a large number of rural households would be derived based on social relations channels, administration channels (i.e., the derived farmers have administrative subordination relations with the pilot farmers), 
technological channels (i.e., the derived farmers have mentoring relationship with the pilot farmers), or market channels (Figure 5). Innovative technologies would spill over through these derivative channels to the derived farmers.

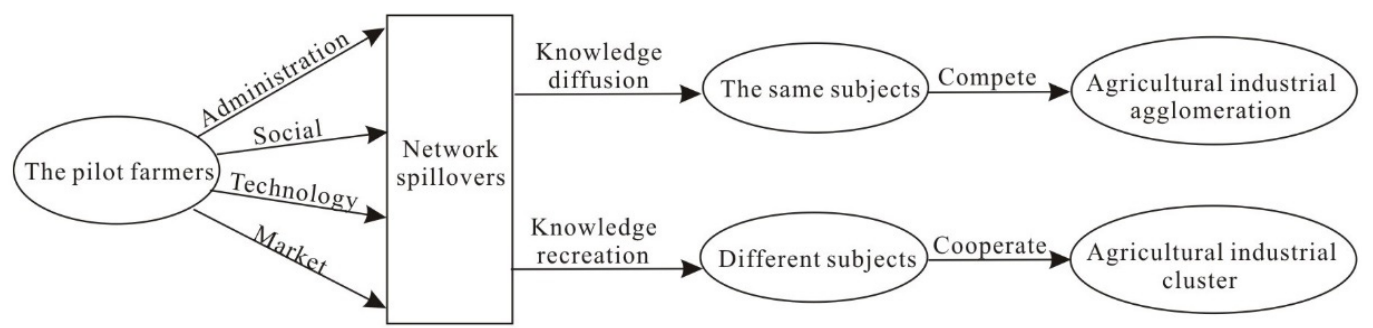

Figure 5. Spinoffs of different type of actors: related diversification.

In the formation of a specialized village, because agricultural production requires specialized but overt knowledge, and as the source of innovative knowledge, the innovation in the pilot farmers would first spread among same-level households within the village. This is because the greater the knowledge gap between the innovation subjects and the receptor, the more difficult the innovation spillover would be. However, if there exists geographical proximity, socio-cultural proximity, and institutional environment proximity, as well as cognitive proximity among the farmers in the same village, the innovation spillover would be more convenient. In this way, the leading farmers can influence more same-type planting households or family farms, and they would naturally gather in the same rural community. In this way, an industrial agglomeration that produces a specific product would be formed. The trust and identity of local culture strengthens the local buzz and industrial atmosphere, and more neighbors join in the new planting project, forming a specialized village.

Shouguang vegetable industry became famous in 1989 when Wang Leyi, secretary of Sanyuan Village, Sunjiji Town, Shouguang City, introduced greenhouse vegetables. In last month of 1988, Wang Leyi saw the local business opportunity of developing out-of-season vegetables from fresh cucumbers bought by his cousin, and hired Han Yongshan, a vegetable grower from Wafangdian City of Liaoning Province, to guide the village in building 17 winter-warm vegetable greenhouses, thereby setting off the first technological revolution in anti-season vegetable cultivation. Such technology of greenhouse construction rapidly spilled over to others within the village and even to those outside the village. In 1990, the government invested RMB 1 million in establishing a scientific and technological service hall integrating R\&D promotion, commodity services and popular science training, as well as inviting experts to visit the local area to provide technological guidance, and supporting the promotion of greenhouse construction technology and the creation of large-scale greenhouses. From 1992 to 1993, guided by professional technical personnel, Wang Leyi successfully cultivated pollution-free vegetables and such new species as large cherries, grapes, and spirulina, sparking the second revolution of Shouguang's vegetables: the 'green revolution'. In 1996, Wang Leyi led the people to successfully test a new generation of high-standard greenhouses integrating irrigation, formwork retaining walls, electric roller blinds, steel frame support, and computer control. This technological innovation prompted Wang Leyi to establish a roller shutter factory and forge the vegetable trademark of 'Leyi'. Thus, Wang Leyi realized the transformation from a farmer to an entrepreneur. During this period, the villagers of other villages continue to imitate Wang Leyi and develop their own greenhouse vegetable planting. Thus, derived by administrative and technical channels, the number of vegetable greenhouses grew from the original 17 to 5000 in 1990, and to nearly 200,000 in 1995, and more than 4000 traditional farmers have been spun off and transformed into business organizations by absorbing and adopting innovative technologies from seed farmers, which verifies hypothesis 1 of this paper, that is, the local derivation of seed farmers is the main way of the transformation of traditional farmers into enterprises. The greenhouse vegetable planting areas increased to over $33,333 \mathrm{hm}^{2}$ in 1995 , 
and the number of specialized villages increased from 23 in 1990 to 58 in 1995. During that period, Shouguang vigorously promoted the 'ten pollution-free vegetable production technologies' (the first in China); the area grew from $2000 \mathrm{hm}^{2}$ in 1991 to $18,667 \mathrm{hm}^{2}$ in 1995, with an annual output of over 1 billion kg; and more than 10,000 tons of pollution-free vegetables were processed and exported every year, selling well in Japan, South Korea, Hong Kong, Taiwan, Southeast Asia, and the United States. It follows that the seasonal open-air cultivation of vegetables subsequently developed into four-season greenhouse cultivation in Shouguang. The spatial pattern of scale production, regionalization distribution of vegetable planting formed rapidly in the surrounding area of Sunjiaji Town; meanwhile, influenced by farmer spin-offs and knowledge spillovers, a large number of specialized villages formed.

\subsection{Spin-Offs and Innovation Spillover in the Formation Stage of the Agricultural Cluster (1996-2012)}

The formation process of an industrial cluster is also the process of the upgrading and integration of industries in specialized villages. The success of the pilot farmers and their followers will have an overflow and transmission effect on other farmers in the same village or surrounding villages, realizing the situation of 'one farmer helps a village and villages help a town' in the rural area.

Farmers at different levels developed in a local atmosphere of innovation. They gradually evolved into an enterprise or institution. In particular, driven by the entrepreneurial spirit, the pilot farmers often became leading enterprises in their localities.

Upon winning over other farmers by the pilot farmers as followers, if the farmers receiving new knowledge only adopted the innovative knowledge of the pilot farmers, they would practice the same production processes as those by the pilot farmers and would become competitors. However, they simply geographically gather together to share the external economy, and no form a cluster. If the farmers accepted the knowledge spillover and conducted other but relevant production processes, organization, technology, or market innovation on that basis, they would become complementary to the pilot farmers. Competition and cooperation between them, inspired the idea of constant innovation, and a cluster is formed. The complexity of the innovative knowledge is correlated to the competence of the farmers who adopted it. Innovation subjects of different types of planting, processing, services, or intermediary agency are derived, and the related diversification (Boschma and, Iammarino, 2009) of the cluster is formed (Figure 5).

As market scale promotes the division of labor (Smith, 1776), common product markets are formed by many farmers, enterprises, or institutions. More industrial chains link splitoffs. The scope of the industry spreads to cover a greater rural area. It would form division and cooperation between specialized villages.

In the face of a common market and technical challenges, governments and scientific research institutions have participated in the joint solution and promotion of further innovation production and innovative network formation. The local innovation atmosphere helped every participant to do their best to innovate. They cooperated with each other to form an industrial network and a rural industrial cluster.

In this stage, by relying on green technology innovation, the Shouguang vegetable industry promoted the second revolution in vegetable technology, namely the 'green revolution', actively explored the cultivation techniques of green vegetables and organic vegetables, and realized transformation from a quantitative expansion to a quality improvement. The number of specialized villages reached 199 and clear industrial divisions arose among specialized villages. New-type production enterprises in such related fields as pesticides, seeds, fertilizers, and agricultural plastics were spun off and established. There were more than 400 vegetable and agricultural enterprises. Taking enterprises derived from the originals as an example, during the formation of an industrial cluster, the innovative behavior of individual entrepreneurs would inspire imitation in entrepreneurial communities. According to the recollections of Mr. Pei (Chairman of Hongshen Foods 
Co., Ltd. in Shouguang City of Shandong Province, in 1997), while working in a public service unit, discovered that many villagers were growing carrots on a massive scale. Upon learning this, he resigned resolutely. After conducting research in other cities, he returned and established a small-scale carrot processing plant. With the increase in demand, in 2003, Mr. Pei set up a second branch for his business in the local village; in 2004, his operation secured rights to export processed carrots. In 2005, in order to lower import-export costs, he comprehensively exploited the international market and entered into trade relations with many countries. In this process, he continuously improved his machinery equipment. From 1997 to 2000, he helped his friends to start six carrot processing plants with the same level of education and knowledge as his own, forming the Peiling Vegetable Group, Longyuan Food Co., Ltd., Bilong Food Co., Ltd., Sifang Food Co., Ltd., Keshengda Vegetable Products Co., Ltd. and Fuhong Vegetable Food Co., Ltd. All six became leading enterprises developed under the mode of 'company + base + farmer'. In 2000, the success of the First Vegetable Expo in Shouguang City opened a window of external communication for the Shouguang Vegetable Cluster. A professional vegetable trading market was established and later expanded. The Vegetable Industry Association became increasingly standard. After 2000, even more carrot plants were built locally (Figure 6). In addition, scientific research institutes and intermediary service agencies joined and formed a close and open innovation cooperation network with the government and enterprises. At this point, the Shouguang Vegetable Cluster had formed. It can be seen that the pilot farmers (or enterprises) and their derived farmers (or enterprises) specialize in the same or different links of the industrial chain through knowledge dissemination, knowledge adoption and knowledge re-innovation, and jointly realize local industrial specialization and spatial agglomeration. The network-spillover and adoption of innovative knowledge promote the derivation of specialized farmers or enterprises and realize regional agricultural specialization and spatial agglomeration, which verifies hypothesis 2 .

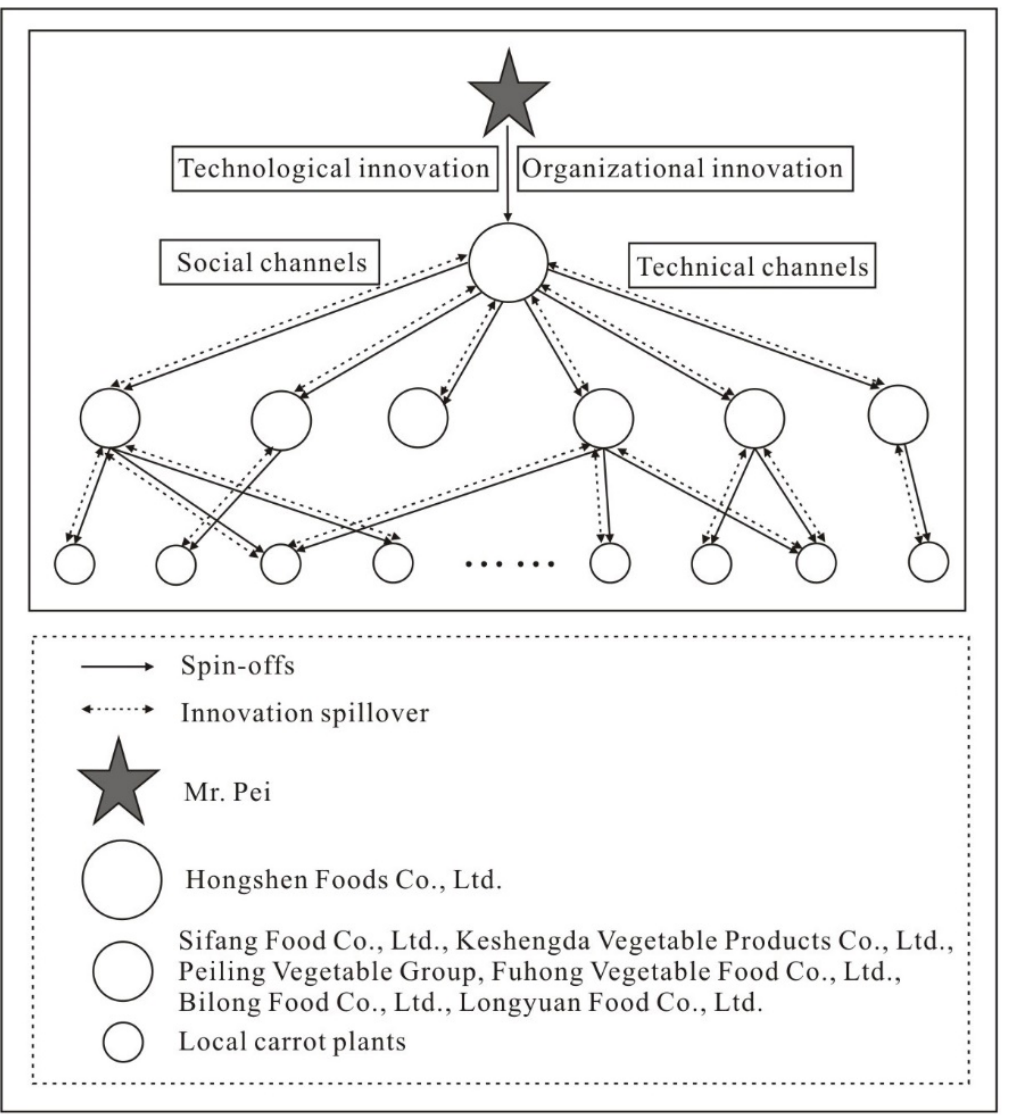

Figure 6. Spinoffs and innovation of carrot processing enterprise. 


\subsection{Innovation System Formation and Spatial Integration Stage (from 2013 to Present)}

Innovation is the driving force of sustainable development of industrial cluster. However, innovation is a systematic engineering, and innovation of one link must be coordinated with other links in order to play an effective role. Therefore, the formation of local agricultural innovation system marks the maturity of industrial clusters. The agricultural innovation system is an agricultural organization and system arrangement composed of diversified innovation subjects, networked innovation process, regional innovation environment, and integrated innovation objectives. The pilot farmers with entrepreneurial spirit in a region, triggered by a certain opportunity, acquire new knowledge or new technology for the development of a new industry, adopt the new knowledge, and successfully establish a start-up enterprise, and their new knowledge flows quickly in the neighboring rural communities and is imitated and adopted. A large number of similar and supporting enterprises or supporting service institutions have been derived [19], which have formed an innovation network together with government departments, university, research institutions and intermediary institutions. The Government has put forward a series of policy arrangements to promote the development of local industries and improve local innovation environment. It can be seen that spin-off and innovation spillover promote the formation of local agricultural innovation system and realize local product innovation, organizational innovation, institutional innovation, technological innovation, and spatial restructuring (Figure 7).

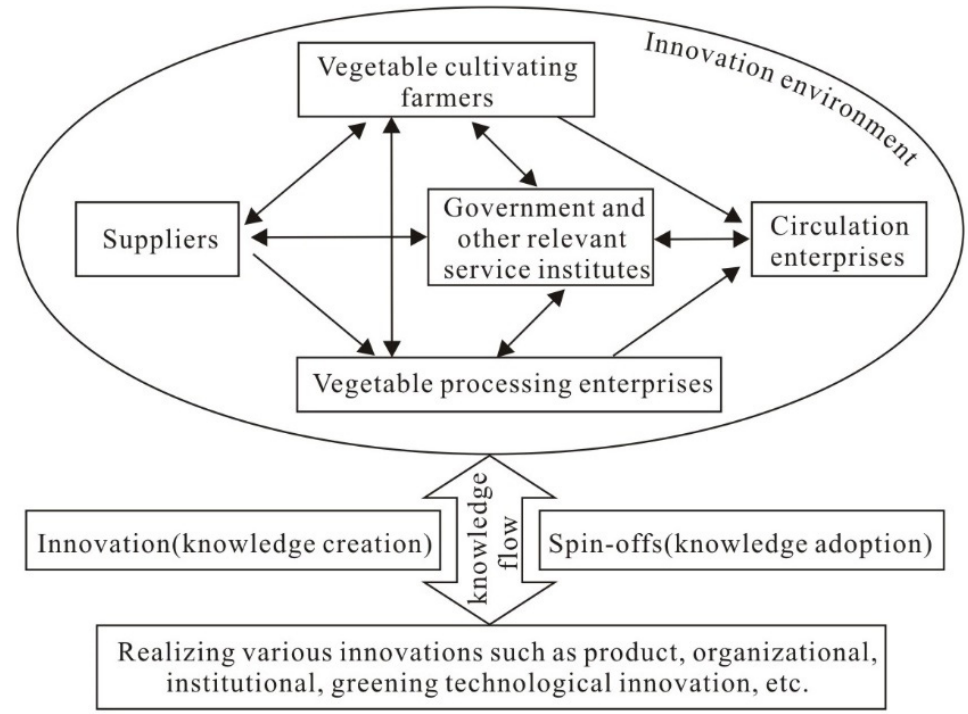

Figure 7. Formation of agricultural innovation system in the cluster area.

After a long period of practice, the technological innovation, product innovation and organizational innovation in the Shouguang Vegetable Cluster were increasing. For example, the vegetable ridge cultivation technique and cultivation techniques of large and small ridges were developed; the construction technology of winter-warm greenhouses was updated from the third generation in 1996 to the seventh generation; and highly practical and popular equipment was invented such as roller shutters, vegetable greenhouse films, greenhouse snow removers, smart storm lamps, plant growth lamps, and waterfertilizer integrated machines. Sci-tech, precise and creative agriculture projects were introduced, including automated computer management, comprehensive biogas utilization, Dutch intelligent mode, solar photovoltaic greenhouses, biological bacterial fertilization, and soilless cultivation, accelerating the development of the vegetable industry towards scientific, ecological and tourism agriculture.

To improve the situation of the decrease in soil fertility and increase in plant diseases and insect pests of perennial planting vegetables, Shouguang City implemented the 'Fertile Vegetable Soil Facilities Project', 'Root Knot Nematode Disease Prevention and Treatment Project', and 'Green Plant Protection project'. By the end of 2015, the whole city had created 
552 'three-quality' (pollution-free, green, and organic) agricultural products (Table 2) and six national geographical indication products. A total of $80 \%$ of the vegetables of the park entered Beijing, Shanghai, Qingdao and more than 17 other large and medium-sized cities.

Table 2. Part enterprises and products certified "green food" certification in Shouguang vegetable industrial cluster in recent years.

\begin{tabular}{|c|c|c|}
\hline Certified Enterprises & Certified Products & Certified Time \\
\hline Minlong Vegetable Professional Cooperative & Zucchini, Tomato, Towel gourd, Eggplant & $2017-10$ \\
\hline Hanxing Vegetable Professional Cooperative & Cherry tomato, Towel gourd & 2018-11 \\
\hline Leyi Vegetable Technology Development Co., Ltd. & $\begin{array}{l}\text { Long eggplant, Beans, Round eggplant, Pepper, } \\
\text { Cherry tomato, Thorn free cucumber, Zucchini, } \\
\text { Kidney bean, Balsam pear, Tomato, } \\
\text { Cucumber, Round pepper }\end{array}$ & $2018-11$ \\
\hline Zhendu Vegetable Professional Cooperative & Colorful pepper & 2018-12 \\
\hline $\begin{array}{c}\text { Hengshuwujiang Agricultural Development } \\
\text { Group Co. Ltd. }\end{array}$ & Pepper, Sweet pepper, Tomato, Cucumber, Eggplant & 2019-01 \\
\hline Qingshuipo Agricultural Products Co. Ltd. & Pepper, Strawberry tomato, Tomato & 2019-07 \\
\hline $\begin{array}{c}\text { Lusheng Agricultural Science and Technology } \\
\text { Development Co. Ltd. }\end{array}$ & $\begin{array}{l}\text { Pumpkin, Tomato, Bell pepper, Watermelon, } \\
\text { Thick-skinned melon } \\
\text { Yam, Pumpkin, Turnip, Carrot, Kidney bean, }\end{array}$ & 2019-07 \\
\hline Aijia Agricultural Development Co. Ltd. & $\begin{array}{c}\text { Tomato, Colorful pepper, Towel gourd, Eggplant, } \\
\text { Cucumber, Pepper }\end{array}$ & 2019-12 \\
\hline Shouguang Vegetable Industry Group Co. Ltd. & $\begin{array}{c}\text { Celery, Eggplant, Pumpkin, Radish, White gourd, } \\
\text { Colorful pepper, Towel gourd, Round pepper, } \\
\text { Tomato, Garlic moss, Green pepper, } \\
\text { Balsam pear, Cucumber }\end{array}$ & 2019-12 \\
\hline
\end{tabular}

Note: The above products are all vegetables (including melons and fruits).

In this stage, in responding to the changes in the market and technology, the government must constantly improve the local investment and innovation environment. For example, the government conducts spatial integration for the purpose of improving the efficiency of land utilization and industry innovation. After 2013, spatial integration was conducted in the Shouguang Vegetable Cluster on the principles of 'concentration, scale operation, and green and organic', thus accelerating the construction of a modern agricultural park covering $2333 \mathrm{hm}^{2}$ with Yangqing Road, Yangtian Road, and Changda Road as the 'Three Ecological Agricultural Corridors'. New technology and products were applied in standardized production, such as the integration of water and fertilizer and soilless culture, and were popularized vigorously in the park in order to accelerate the realization of standardized production. Through spatial integration, the number of specialized villages in Shouguang City was reduced to 109 in 2014, and the spatial pattern of specialized planting, large-scale production and regionalized development was formed at the township level.

Thus, it can be seen that cluster formation accelerates innovation spillover among institutions of government-industry-university-research-users [35], and the formation of the innovative network. These institutions coordinate with each other on the division of labor and jointly innovate. Finally, in a certain scope of the rural area, an agricultural innovation system focused on a specific agricultural product and featuring the integration of the primary, secondary, and third industries is formed, symbolizing the maturity of the agricultural cluster (Figure 7), and hypothesis 3 is tested.

\section{Discussion}

Marshall's original works were concern with an explanation of the competitive advantages of industrial clusters with knowledge spillover, the shared labor market, and the shared intermediate input products. In other words, he concluded that the external economy existed inside the industrial district, but what was the source of the external economy? Romer (1986) quantitatively studied the contribution of the innovation knowledge spillover, that is, external economy of knowledge to economic growth [36]. The Shouguang Vegetable 
Cluster case qualitatively shows that one source of the spatial external economy, i.e., spatial increasing returns to scale, is that the innovative knowledge of the original subjects is adopted by other subjects locally through network spillover, deriving more similar subjects and sharing the knowledge brought by the original cost. If the new behavioral subjects were not derived and the external economy was hidden, the external economy would become clarified and enlarged by the newly derived subjects. This case study also shows that agricultural agglomeration can also bring spatial increasing returns to scale, rather than constant returns to scale.

The innovative ideas of the original subjects in traditional rural areas are spread by the genetic, academic, and geographic relationships, so entrepreneurs are rooted in the original social network and local culture via the derivative network. Because of the natural geographic, social, and cultural proximity that are similar to a knowledge base, successful innovative knowledge has its fastest spillover and adoption locally, thereby promoting the increase in agricultural agglomeration in the spatial returns to scale. In particular, the chain of agricultural industries has become longer, the market division space is now larger, and the technical threshold is now relatively lower than before. Under the circumstances of a sufficiently large produce market capacity, this division is continuously refined, the industrial chain links continuously increase, contact between subjects becomes closer, network nodes become further diversified, cooperation, and innovation emerge continuously, and the agricultural industrial cluster becomes mature.

The formation of an agricultural industrial cluster is an effective method for the promotion of traditional agricultural transformation and rural revitalization. For the cultivation of agricultural clusters in developing countries, especially Shandong Province, China, the following suggestions are put forward according to the results of this article and the knowledge and experience from the functioning of agricultural clusters from other provinces of China and abroad: (1) The entrepreneurial spirit of farmers should be encouraged in order to secure innovative opportunities suitable for the local conditions; (2) the quantification, simplification, circulation, and mobility of knowledge should be improved; (3) the quality and knowledge adoption capacity of farmers should be enhanced through professional training; (4) various types of entrepreneurship should be encouraged so as to promote the farmers' enterprise evolution; (5) different channels of innovation spillover shall be dredged in order to establish the innovative network; (6) the innovation environment of the area shall be constructed to allow the establishment of the local agricultural innovation system. The selection of different types of agricultural cluster cases for the quantitative analysis of the microcosmic mechanisms of agricultural clusters should be the orientation for subsequent research.

\section{Conclusions}

Based on a case study of the formation process and mechanism of Shouguang vegetable industrial cluster in Shandong Province, three hypotheses proposed in this article are verified. It can be seen that:

(1) The local derivation of seed farmers is the main path in the transformation of traditional farmers into enterprises. Derivation and innovation spillover during the formation of an agricultural cluster would produce the scale effect, economic effect, social effect, and spatial effect. Matching knowledge of different complexity with adoption subjects of different levels of ability is the key to the occurrence of beginning and the spread of innovation spillover. Levels of such spread were often in-line with social stratification form the relevant diversity of behavioral subjects.

(2) The network-spillover and adoption of innovative knowledge promote the derivation of specialized farmers or enterprises and realize regional agricultural specialization and spatial agglomeration. Path dependence resulting from entrepreneurial spirit delivery and related technology inheritance will trigger the self-reinforcing mechanisms of industrial cluster formation, thus leading to the reconstruction of the spatial structure of rural industry. 
(3) The formation of the agricultural cluster was the result of joint effects of spin-off derived from the entrepreneurial spirit of the farmers, network-spillover of different agricultural innovations, and spatial integration of the agricultural landscape. This can be illustrated as pilot farmers with entrepreneurial spirits introduced or pursued innovative knowledge (knowledge production or introduction) $\rightarrow$ innovation spillover (knowledge diffusion) $\rightarrow$ derivation (adopted knowledge) $\rightarrow$ new subject entrepreneurship $\rightarrow$ industrial agglomeration $\rightarrow$ secondary innovation (complementary knowledge, reproduction and recreation) $\rightarrow$ derivation again (knowledge adopted again) $\rightarrow$ agricultural cluster formation $\rightarrow$ acceleration of agricultural innovation system perfection and industrial spatial integration. The formation of local agricultural innovation system marks the maturity of agricultural clusters.

Author Contributions: Conceptualization, E.L.; methodology, E.L.; formal analysis, E.L.; investigation, Y.X.; data curation, S.R.; writing — original draft preparation, E.L.; writing-review and editing, J.L.; visualization, Y.X.; supervision, E.L. All authors have read and agreed to the published version of the manuscript.

Funding: This research was funded by National Natural Science Foundation of China (41971222), the program for Innovative Research Team (in Science and Technology) in University of Henan Province (21IRTSTHN008), Philosophy and Social Science Planning Project of Henan Province (2019BJJ019).

Acknowledgments: We wish to thank the kind local households, enterprises and cooperatives who were willing to be interviewed and the local government departments of Shouguang City for providing relevant information.

Conflicts of Interest: The authors declare no conflict of interest.

\section{Notes}

An SV is a rural settlement in which households engage in production or some interrelated commodities or service activities. Such activities constitute the main body of the social and economic values of this village (Li et al., 2010). For each SV, at least 50 percent of the entire village's output was produced by one or just a few particular leading industries, offering unique, marketable products by using certain scientific and technological processes; revenue from the leading industries or products dominated the village's total income and was the main source of household incomes; a majority of farmers were employed by the leading industries or participated in the production of the specialized products and corresponding business activities [9].

\section{References}

1. Porter, M. The Competitive Advantage of Nations; Macmillan: London, UK, 1990.

2. Galvez-Nogales, E. Agro-Based Clusters in Developing Countries: Staying Competitive in a Globalized Economy; Agricultural Management, Marketing and Finance Occasional Paper; FAO: Rome, Italy, 2010.

3. Winder, G. The North American Manufacturing Belt in 1880: A Cluster of Regional Industrial Systems or One Large Industrial District? Econ. Geogr. 2010, 75, 71-92.

4. Miyagi, K. Development and Issues of the Information-Communication Industry Cluster in an Island Economy: A Case Study of the Ryukyu Islands. Reg. Stud. 2006, 2, 163-176.

5. Cefis, E. Industrial Dynamics and Cluster: A Survey. Reg. Stud. 2014, 49, 10-27.

6. Nie, P.; Wang, C.; Li, K. Cooperation of firms yielding industrial clusters. Area 2020, 52, 731-740. [CrossRef]

7. Zhao, L.; Ruan, J.; Shi, X. Local industrial policies and development of agricultural clusters: A case study based on a tea cluster in China. Int. Food Agribus. Manag. Rev. 2021, 24, 267-288. [CrossRef]

8. Sporleder, T. The Importance of the Food and Agriculture Cluster to the Economy of Licking County Ohio; AED Economics Report AEDE-RP-0118-09; The Ohio State University: Columbus, OH, USA, 2009.

9. Qiao, J.; Lee, J.; Ye, X. Spatiotemporal Evolution of Specialized Villages and Rural Development: A Case Study of Henan Province, China. Ann. Am. Assoc. Geogr. 2016, 106, 57-75. [CrossRef]

10. Piore, M.; Sable, C. The Second Industrial Divide: Possibilities for Prosperity; Basic Books: New York, NY, USA, 1984.

11. Porter, M. Clusters and the new economics of competition. Harv. Bus. Rev. 1998, 76, 77.

12. Saxenian, A. Regional Advantage: Culture and Competition in Silicon Valley and Route 128; Harvard University Press: Cambridge, MA, USA, 1994.

13. Gordon, I.; Mccann, P. Industrial Clusters: Complexes, Agglomeration And/Or Social Networks. Urban Stud. 2013, 37, 513-532. [CrossRef]

14. Scott, A. Capitalism and Urbanization in a New Key? The Cognitive-Cultural Dimension. Soc. Forces 2007, 85, 1465-1483. [CrossRef] 
15. Guiliani, E. What Drives Innovative Output in Emerging Clusters? Evidence from the Wine Industry. SPRU Working Paper Series, 2008. Available online: https://ideas.repec.org/p/sru/ssewps/169.html (accessed on 4 January 2022).

16. Ponds, R.; van Oort, F.; Frenken, K. Innovation, spillovers and university-industry collaboration: An extended knowledge production function approach. J. Econ. Geogr. 2010, 10, 231-255. [CrossRef]

17. Wang, J. Industrial clusters in china: The low road vs. the high road in cluster development. In Development on the Ground: Clusters, Networks and Regions in Emerging Economies; Scott, A., Golifoli, G., Eds.; Routeledge: London, UK, 2007; Chapter 7; pp. 145-164.

18. Yang, Y.; Li, E. A theoretical framework and empirical analysis of the formation mechanism of green agricultural industry cluster: A case study of the Shouguang vegetable industry cluster in Shandong Province. Resour. Sci. 2021, 43, 69-81. (In Chinese) [CrossRef]

19. Li, E. The formation, evolution and innovative development of agricultural clusters in China: Case of the cluster nature of "Shouguang Mode". Sci. Geogr. Sin. 2020, 40, 617-627. (In Chinese) [CrossRef]

20. Marshall, A. Principles of Economics; Macmillan: London, UK, 1890.

21. Becattini, G. The Marshallian industrial district as a socioeconomic notion. In Industrial Districts and Inter-Firm Co-Operation in Italy; Pyke, F., Becattini, G., Sengenberger, W., Eds.; IILS: Geneva, Switzerland, 1990.

22. Fujita, M.; Krugman, P.R.; Venables, A. The Spatial Economy: Cities, Regions, and International Trade; MIT Press: Cambridge, MA, USA, 1999. [CrossRef]

23. Li, E.; Li, X.; Liu, Z. Relationships and Evolving Networks of Rural Manufacturing Clusters: A Case Study in Yucheng County, Henan Province of China. Chin. Geogr. Sci. 2011, 21, 364-376. [CrossRef]

24. Li, E.; Li, X. On the Network Nature of Industrial clusters. Econ. Surv. 2007, 24, 66-70. (In Chinese) [CrossRef]

25. Balland, P.; De Vaan, M.; Boschma, R. The dynamics of interfirm networks along the industry life cycle: The case of the global video game industry, 1987-2007. J. Econ. Geogr. 2011, 13, 741-765. [CrossRef]

26. Golman, R.; Klepper, S. Spinoffs and clustering. Rand J. Econ. 2016, 47, 341-365. [CrossRef]

27. Boschma, R. Do spinoff dynamics or agglomeration externalities drive industry clustering? A reappraisal of Steven Klepper's work. Ind. Corp. Change 2015, 24, 859. [CrossRef]

28. Klepper, S.; Sleeper, S.D. Entry by spinoffs. Manag. Sci. 2005, 51, 1291-1306. [CrossRef]

29. Romer, P.M. Endogenous Technological Change. J. Political Econ. 1990, 98, S71-S102. [CrossRef]

30. Grossman, G.; Helpman, E. Innovation and Growth in the Global Economy; Mit Press: Cambridge, MA, USA, 1991; Volume 1, pp. 323-324.

31. Carlino, G.A. Knowledge spillovers: Cities' role in the new economy. Bus. Rev. 2001, 7, 17-26.

32. Cohen, W.; Levinthal, D. Absorptive capacity: A new perspective on learning and innovation. Adm. Sci. Q. 1990, 35, 128-152. [CrossRef]

33. Boschma, R.; Iammarino, S. Related Variety, Trade Linkages, and Regional Growth in Italy. Econ. Geogr. 2009, 85, $289-311$. [CrossRef]

34. Yin, R.K. Case Study Research: Design and Methods; Applied Social Research Methods Series; SAGE Publications: New York, NY, USA, 1989; Volume 5. [CrossRef]

35. Li, E.; Yao, F.; Xi, J.; Guo, C. Evolution Characteristics of Government-industry-university-research Cooperative Innovation Network for China's Agriculture and Influencing Factors: Illustrated According to Agricultural Patent case. Chin. Geogr. Sci. 2018, 28, 137-152. [CrossRef]

36. Romer, P. Increasing Returns and Long-Run Growth. J. Political Econ. 1986, 94, 1002-1037. [CrossRef] 